\title{
Programmed and triggered actions to rapid load changes during precision grip
}

\author{
R.S. Johansson and G. Westling \\ Department of Physiology, University of Umeå, S-901 87 Umeå, Sweden
}

Summary. A test object (grip apparatus) was held at its upper part using a precision grip. Small balls were dropped into a target cup at the bottom of the apparatus. The grip force, the load force (vertical lifting force) and the vertical movement were measured. Electromyographic activity (e.m.g.) was recorded from four antagonist pairs of hand/arm muscles primarily influencing the grip force or the load force. The balls were dropped either by the subject during a bimanual task, or unexpectedly by the experimenter. When the subject dropped the ball, preparatory actions occurred before the rapid increase in the vertical load caused by the impact. These actions appeared ca. $150 \mathrm{~ms}$ prior to the impact and involved a grip force increase and a lifting movement of the grip apparatus. The e.m.g. activity increased in all eight of the hand and arm muscles, indicating a general stiffening of the hand/arm system prior to the impact. Furthermore, the preparatory actions were programmed adequately for the size of the load force step at the impact, i.e. an adequate safety margin to prevent slips was preserved during the critical period of the impact. Thus, variations in this step caused by changes in (i) the weight of ball, (ii) the weight of the grip apparatus and (iii) the length of the drop were adequately taken into account during the programming of these actions. In addition, the frictional condition between the skin and the grip surface was also taken into account. The relevant sensory information apparently was obtained during the handling of the ball and the grip apparatus prior to the drop. There were also task-related automatic muscle responses triggered by the impact. These responses, which also served to stiffen the hand/arm system, were most pronounced during unexpected load changes, but they appeared too late to prevent slips. However, if no overall slip occurred,

Offprint requests to: R.S. Johansson (address see above) the triggered responses were functional in the sense that they helped to quickly restore the safety margin and the vertical position of the object.

Key words: Precision grip - Motor control - Human hand - Somatosensory input - Long-latency reactions - Anticipatory mechanisms - Sensori-motor memory

\section{Introduction}

While lifting and holding objects using the precision grip between the tips of the fingers and the thumb, the balance between the grip force and the load force (vertical lifting force) is accurately controlled (Johansson and Westling 1984b; Westling and Johansson 1984). Primarily, there is a programmed parallel change in the grip force and the load force. The ratio between these two forces is automatically adapted to the friction between the skin and the object, providing a fairly small safety margin to prevent slips. This adaptation takes place on the basis of tactile input from the fingers which intermittently updates a sensorimotor memory which, in turn, influences the force ratio (Johansson and Westling 1987). Thus, the manipulative task is apparently underwritten by a program to prevent slips. However, during everyday tasks there are often further manipulative actions superimposed on the basic grip. Occasionally, these may involve very rapid changes in the load forces which tend to cause slips. However, accidental slips rarely occur in situations during which the changes are actively generated by the subject. Hence, it seems likely that such load force changes somehow will be met by preparatory actions strengthening the grip - a broad repertoire of anticipatory motor responses have been described for various voluntary movements in other contexts (e.g. 
Belenkii et al. 1967; Mellvill-Jones and Watt 1971; Diets et al. 1981; Hugon et al. 1982). In contrast, if there are sudden, unexpected load increases any compensatory actions will be triggered by sensory signals. In the present study the subject held a test object with a precision grip and we examined the nature of the various compensatory actions which occurred when the load was increased rapidly by dropping a small ball onto the test object. The ball was dropped either by the subject during a bimanual task, or unexpectedly by the experimenter. Indeed, we found that sophisticated preparatory actions occurred soon before the impact when the ball was dropped by the subject. These served to prevent slips and excessive position deviations. There were also automatic "long-latency" responses triggered by somatosensory input elicited by the impact. These were particularly pronounced during unexpected load changes.

\section{Methods}

Ten healthy, right-handed subjcts ( 5 women and 5 men, 22-44 years old) participated in the present study. The subject sat in a chair with his/her right upper arm parallel to his/her trunk, and with the unsupported forearm extending anteriorly. In this position, he/she was asked to lift a test object (here denoted as the grip apparatus) from a table by grasping it between the tips of the index finger and thumb of the right hand. The lifting movement mainly involved a flexion of the elbow joint. When the grip apparatus was held about $10 \mathrm{~cm}$ above the table, a sudden increase in the load force was introduced as described below. Five to ten min prior to the experiment the subject washed his/her hands with soap and water.

\section{Apparatus}

The grip apparatus, illustrated in Fig. 1, was a modified version of one earlier described (Johansson and Westling 1984b). At the upper part of the apparatus there were two replaceable discs (diameter: $30 \mathrm{~mm}$ ) mounted in two vertical parallel planes (distance: $30 \mathrm{~mm}$ ). These were the parts gripped by the subject. Between these surfaces there was a transducer package to continuously measure the grip force $(0-120 \mathrm{~Hz})$, the vertical lifting force (denoted as the load force; $0-120 \mathrm{~Hz}$ ), and the vertical movements $(0-560 \mathrm{~Hz})$. An accelerometer was attached to record mechanical transients $(10-600 \mathrm{~Hz}$ ). Two vertical metal rods (length $21 \mathrm{~cm}$, $10 \mathrm{~cm}$ apart) were mounted at the base of the transducer package. At their lower ends a horizontally oriented metal plate was attached. An exchangeable weight, the top part of which consisted of a "cup" with a flat bottom (diameter: $9 \mathrm{~cm}$ ), was placed on this plate. In this target cup, plastic balls (5 $\mathrm{cm}$ diameter) with a core of lead were dropped either by the subject or by the experimenter. A spherical object was chosen because it provided a definite moment of collision. Balls of five different weights were used $(100,200$ $300,400,500 \mathrm{~g}$ ), and all had the same visual appearance. To reduce the rebound of the balls, the bottom of the target cup was lined with $15 \mathrm{~mm}$ thick sponge rubber. The rebound coefficient was ca. 0.3 as when the touched discs of the grip apparatus were firmly anchored to a heavy steel framework. (This coefficient (e) was calculated on the basis of the following eqn.: $\mathrm{e}=\sqrt{\mathrm{Hr} / \mathrm{Ho}}$ where Ho is the distance the ball was allowed to fall by the force of gravity and $\mathrm{Hr}$ is the height of the rebound.)

To control the length of the drop, a rubber band was stretched horizontally between the two vertical rods of the grip apparatus (Fig. 1). Prior to its release, the ball had to be positioned just beneath the rubber band. Between trials the experimenter could change the vertical position of the rubber band in calibrated steps.

\section{Experiments}

Three different types of experiments were performed. If not otherwise specified, the grip apparatus weighted $400 \mathrm{~g}$, the ball weighted $300 \mathrm{~g}$, the grip surfaces were suede, and the drop was 4 $( \pm 0.5) \mathrm{cm}$

Subject dropped the ball. The preparatory and triggered actions that arose when the subject let the ball fall was examined. After the grip apparatus had been lifted, the subject picked up the ball from the table using the contralateral hand and positioned it under the rubber band. The ball was then released. After a while the subject was asked to pick up the ball from the target cup and to hold it above the table for some time before replacing it on the table. Finally, the grip apparatus was replaced and released. To obtain reproducible timing the following verbal instructions were recorded on magnetic tape and played back during each trial: "Lift the apparatus", - (2,5 s delay $)$-, "lift the ball", $-(2.5 \mathrm{~s}$ delay $)-$, "drop the ball", - (4 s delay) -, "lift the ball", - (4 s delay) -, "replace the ball", - (2 s delay) -, "replace the apparatus". The tape was automatically rewound during the intervals between the trials $(8 \mathrm{~s})$. In order to teach the subject how to follow the instructions, the tape was played while the experimenter performed two (or three) trials.

Four different series of 22 trials each were run. To resolve influences by ( 1 ) the weight of the ball, $100 \mathrm{~g}, 300 \mathrm{~g}$, and $500 \mathrm{~g}$ balls were pseudorandomly presented. To study influences of (2) the weight of the grip apparatus, its weight was varied unpredictably between $200 \mathrm{~g}, 400 \mathrm{~g}$ and $800 \mathrm{~g}$ without changing its visual appearance. Influences of (3) the friction between the object and the skin were resolved by pseudorandomly changing the grip surface between the silk (most slippery material), suede, and sandpaper (least slippery material) (Johansson and Westling 1984a). The variations in surface material were made without changing the visual appearance of the grip apparatus (see Johansson and Westling 1984b). Finally, influences of (4) the length of the drop were studied by pseudorandomly varying the distance between $2( \pm 0.5) \mathrm{cm}, 4( \pm 0.5) \mathrm{cm}$ and $8( \pm 0.5) \mathrm{cm}$.

Preparatory actions in isolation while the subject dropped the ball. In this experiment the subjects performed 80 trials with the same instructions. However, in 24 randomly-selected trials the experimenter prevented the impact of the ball $(400 \mathrm{~g})$ whereas the ball was allowed to hit the target cup in the remaining 56 "normal" trials. To prevent the utilization of visual signals the subject was instructed to firmly close his/her eyes after the ball had been positioned beneath the rubber band and keep them closed until the second "lift the ball" instruction was heard. Control trials in which (1) the subject was free to see and (2) the eyes were closed but with no interferences by the experimenter were also performed

Experimenter dropped the ball. In this experiment, examining actions triggered by the impact, the subject was asked to lift the grip apparatus and hold it ca. $10 \mathrm{~cm}$ above the table, and $10 \mathrm{~s}$ later to replace it (inter-trial interval, $4 \mathrm{~s}$ ). The subject was sightless throughout (except for certain control series described in Results). To minimize possible preparatory actions, the moment at which 
the experimenter dropped the ball was varied randomly between $1.5 \mathrm{~s}$ and $8.5 \mathrm{~s}$ after the lift instruction. For details concerning the balls that were used, see Results.

In all experiments the subject wore ear phones and all verbal instructions were presented through these. They also strongly reduced ambient noise in the room.

Electromyography (e.m.g.)

In separate lifting experiments on 5 of the subjects, electrical activity was recorded simultaneously from four antagonist pairs of hand/arm muscles: two intrinsic hand muscles, the first dorsal interosseous and the abductor pollicis brevis; two extrinsic hand muscles, the abductor pollicis longus and the flexor pollicis longus; two wrist muscles, the flexor carpi ulnaris and the extensor carpi radiales; and two muscles acting over the elbow, the brachioradialis and the triceps brachii. A pair of flexible silver-coated PVC-electrodes (4 mm diameter, $15 \mathrm{~mm}$ spaced along the muscie) filled with conducting jelly was applied to the skin over the belly of each muscle. The e.m.g. signals were obtained by differential recording, amplified $(6 \mathrm{~Hz}-2.5 \mathrm{kHz})$ and rectified using a rootmean-square (r.m.s.) processor with rise and decay time constants of $1 \mathrm{~ms}$ and $3 \mathrm{~ms}$, respectively. For further details concerning the actions of the muscles during the present lifting task and the recording procedures, see Johansson and Westling 1988.

\section{Data collection and analysis}

The grip force, the load force, the vertical position and the r.m.s. processed e.m.g. signals were stored and analyzed using a computer system. These variables were each sampled at $500 \mathrm{~Hz}$ by a 12 . bit A/D converter. For each trial, the data acquisition started ca. $1 \mathrm{~s}$ prior to the moment the grip apparatus was initially touched and lasted until the subject no longer touched it. An indication of the period the ball was handled by the subject was also sampled by using a microswitch to determine whether or not the ball resided on the table.

The ratio between the grip force and the load force as a function of time was calculated by the computer. To prevent slips this ratio must exceed a critical value determined by the coefficient of friction between the skin and the object. Estimates of the relevant critical ratios were obtained at the end of each series of trials (for procedure see Johansson and Westling 1984a).

During averaging of trials, with certain exceptions denoted in the results section, each trial was synchronized in time at the moment of the impact which was measured by the accelerometer attached to the grip apparatus (Fig. 1). The e.m.g. analysis was always based on averaged data obtained from individual subjects. The latency measurements given in the text refer to the ranges observed for all subjects.

\section{Results}

\section{Sudden load increase produced by the subject}

Figures $2 \mathrm{~A}$ and $\mathrm{B}$ show the results from the experiment in which the subject dropped a ball into the "cup" of the grip apparatus held in the contralateral hand (Fig. 1). The grip and load forces exerted on the grip apparatus as well as its vertical position are shown for two sample trials (different subjects).
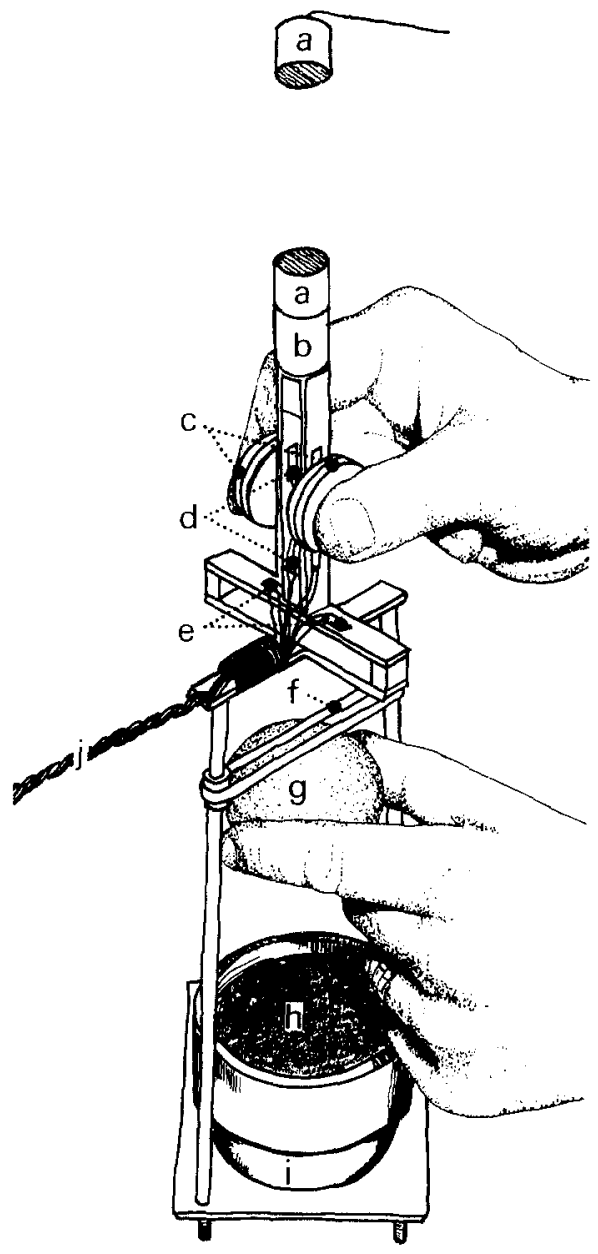

Fig. 1. Schematic drawing of the grip apparatus. a - vertical position transducer with an ultrasonic receiver in the ceiling of the laboratory and a transmitter in the test object, b-accelerometer, c - exchangeable discs, $\mathrm{d}$ and $\mathrm{e}$ - strain-gauge force transducers for measurement of grip force and load force (vertical lifting force), $\mathrm{f}-$ movable rubber band, $\mathrm{g}$ - ball, $\mathrm{h}$ - target cup with flat bottom lined with sponge rubber, $\mathrm{i}-$ exchangeable weight. The balls dropped into the cup by the subject or the experimenter

Arrowheads indicate the period during which the subject handled the ball. During the lifting of the grip apparatus, there was a parallel increase in the grip force and the load force as previously described and a static phase was attained after the intended vertical position was reached (Johansson and Westling 1984b). During this phase the ball was picked up from the table with the contralateral hand, positioned at the appropriate height and then released. For four of the ten subjects, there was often a small increase of the grip force when the ball was picked up (first arrowhead, Fig. 2B). The sudden increase in the load force was due to the ball hitting the target cup. The load force step essentially consisted of a static component corresponding to the 

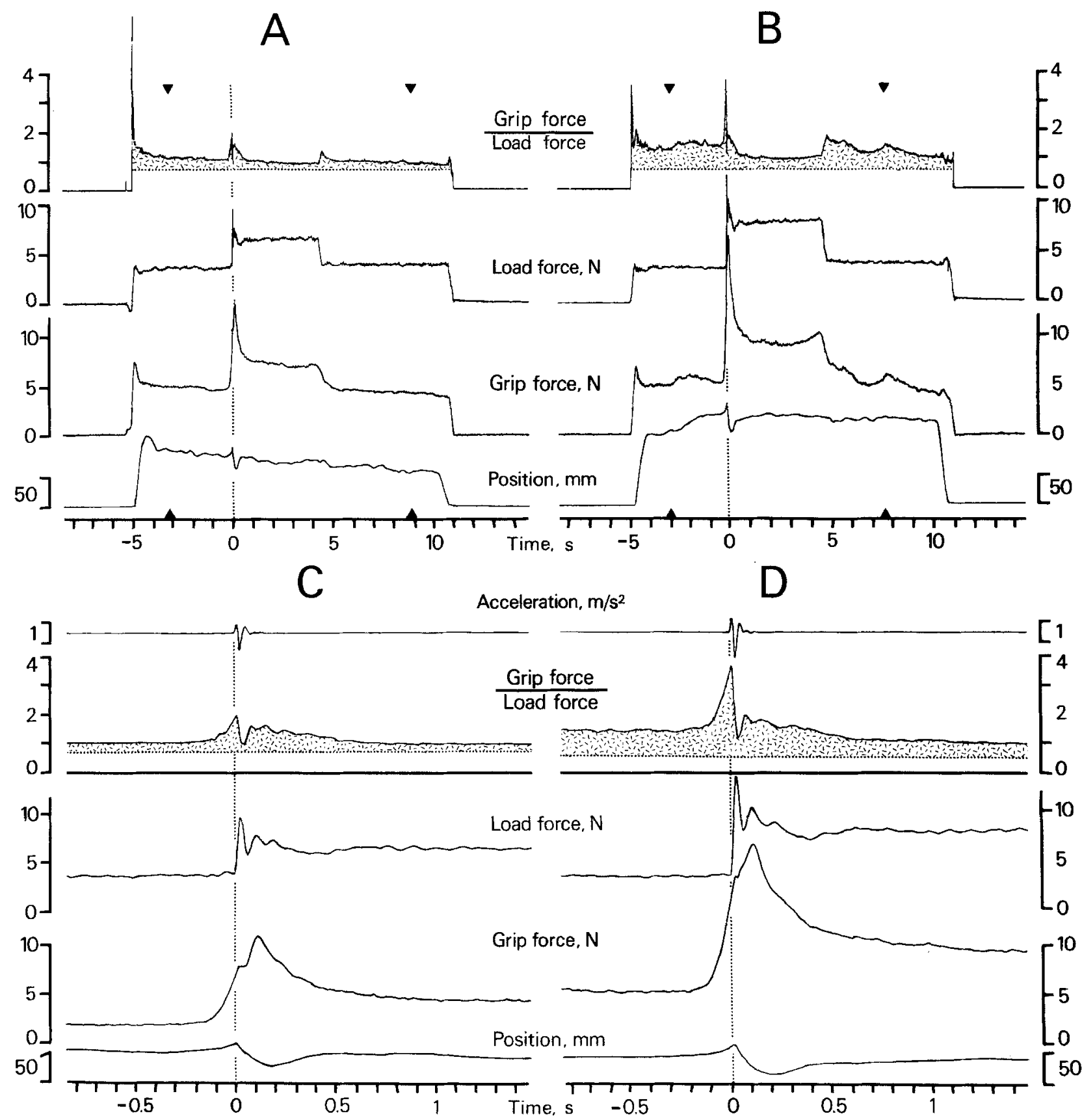

Fig. 2A-D. Load force, grip force, grip force/load force ratio and vertical position as a function of time for two sample trials by two subjects showing somewhat different motor behavior. Subject dropped the ball. $\mathbf{A}$ and $\mathbf{B}$ Complete trial. Arrowheads indicate when the ball was lifted and released with the contralateral hand, respectively. $\mathbf{C}$ and $\mathbf{D}$ Parts of the trials in $\mathbf{A}$ and $\mathbf{B}$ on an expanded time scale. Top trace shows the accelerometer signal. The small notch in the grip force signal at the impact (particularly pronounced in $\mathbf{C}$ ) is an artifact related to the mechanical construction of the grip apparatus. A-D Vertical dotted lines indicate the moment the ball hits the grip apparatus (time $=$ 0 ). Horizontal lines in the ratio graphs show estimated slip ratios and shaded areas indicate the safety margin to prevent slips. Subject in $\mathbf{B}$ and $\mathbf{D}$ showed an extremely high safety margin. Grip surface suede. Weight of grip apparatus $400 \mathrm{~g}$. Weight of ball $300 \mathrm{~g}$ in $\mathbf{A}$ and $\mathbf{C}$ and $500 \mathrm{~g}$ in $\mathbf{B}$ and $\mathbf{D}$

weight of the ball and a dynamic component (peak) corresponding to the kinetic impulse transferred to the hand due to the change in the momentum of the grip apparatus. The later load force changes due to the kinetic impulse were complex and were probably related to rebounding and to accelerations and decelerations caused by reactive movements of the handarm system (see below). After the impact there was 
also a rapid downward movement of the grip apparatus soon followed by a critically damped repositioning.

As illustrated in Fig. 2C, D, the grip force increased prior to the impact. This increase started ca. $150 \mathrm{~ms}$ before the load force step and continued some time (ca. $100 \mathrm{~ms}$ ) after the load peak. There was also a preparatory lifting of the grip apparatus during the period of the preparatory grip force increase. This finding supports the idea that the muscle commands accounting for the grip force and for the lifting movement are coordinated in the sense that they change in parallel (Johansson and Westling 1984b). At the impact, the momentum related to this lifting movement would tend to counterbalance the momentum of the ball and thus reduce the downward movement of the object/hand. All of the preparatory responses were quite reproducible from trial to trial (for example see Fig. 5A).

As seen in Fig. 2, during the static phase before the preparatory responses, the ratio between the grip force and the load force exceeded the minimum ratio required to prevent slips and provided a fairly constant safety margin (cf. Westling and Johansson 1984). This ratio increased during the preparatory grip force increase. At the impact the ratio dropped abruptly to a minimum which was not very much lower than the static-phase ratio. Even at the critical point when the force ratio was minimum, an adequate safety margin to prevent slips was thus maintained. In the absence of the preparatory increase the object would have been dropped.

After its peak, the grip force decayed to a new, higher static value. For most subjects, the force ratio returned to approximately the same value as during the static phase prior to the drop, because the grip force was appropriately adjusted to the new, higher, weight of the grip apparatus (Fig. 2A, also cf. Fig. 6 in Johnsson and Westling 1984b). For the four subjects which showed a clear increase in grip force when the ball was picked up with the contralateral hand, the force ratio generally attained a lower value (Fig. 2B). These subjects all habitually used high safety margins while just holding the grip apparatus still in air, i.e. the safety margin was $40-50 \%$ of the employed grip force (for inter-individual variation in safety margin see Westling and Johansson 1984).

While the ball was picked up from the grip apparatus, the decrease in the load force was accompanied by a decline in the grip force until the forces had returned to levels similar to those seen prior to the dropping of the ball. However, the decline in the grip force generally extended over a longer period than the rapid decrease in the load force, and the ratio between the two forces was temporarily

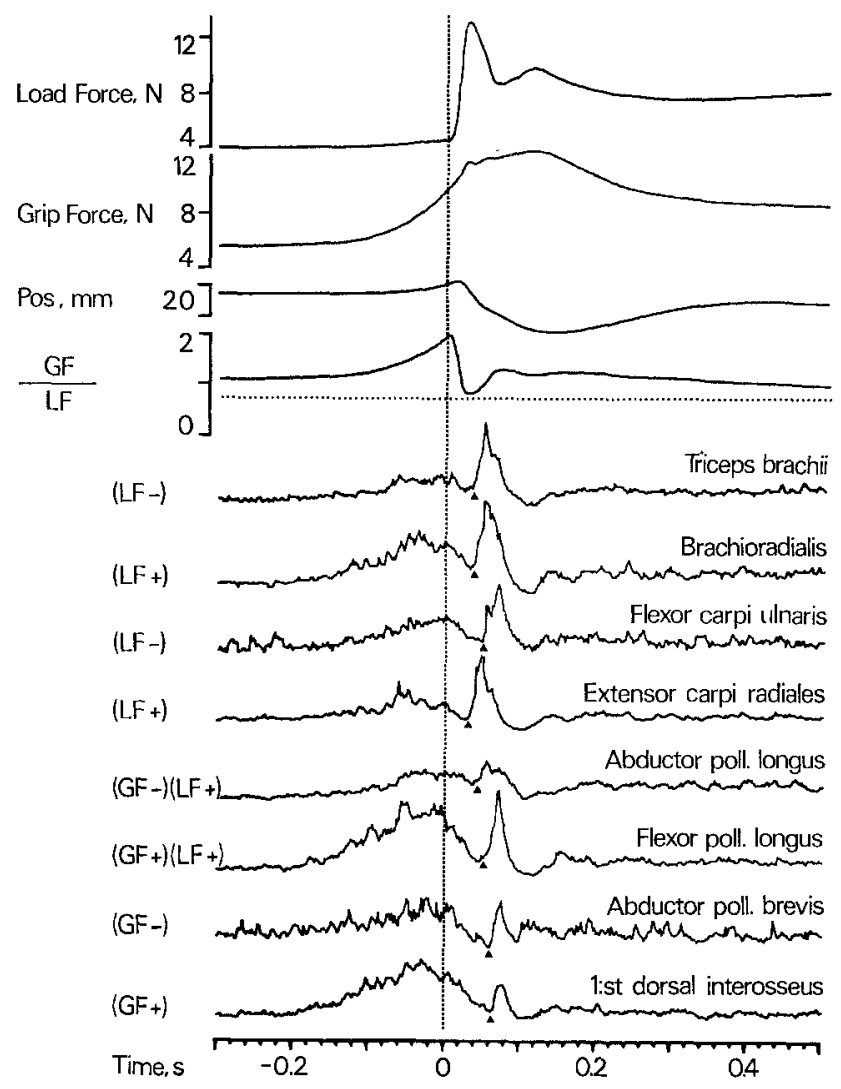

Fig. 3. Mechanical actions and e.m.g. activity associated with the rapid load force increase caused by the subject dropping the ball. Load forces, grip force, vertical position, grip force/load force ratio and r.m.s. processed e.m.g. signals from eight separate hand/arm muscles as a function of time. Horizontal dotted line indicates estimated slip ratio. Vertical dotted line (time $=0$ ) indicates the moment the ball $(400 \mathrm{~g})$ hits the grip apparatus $(400 \mathrm{~g})$. The primary actions of the various muscles regarding their influences on the load and grip forces are indicated by LF+ (load force increase), LF- (load force decrease), GF+ (grip force increase) and GF- (grip force decrease). Arrowheads indicate take off points for the triggered e.m.g. peaks. Grip surface suede. Data from 25 trials by a single subject are aranged after synchronization in time at the moment the ball hit the grip apparatus

increased (especially apparent in Fig. 2B). Occasionally, there was also a small, temporary increase in the grip force when the ball was placed back on the table.

Pattern of muscle activation. The e.m.g. traces in Fig. 3 illustrate the pattern of muscle activation associated with the impact. Four antagonist pairs are shown, including intrinsic and extrinsic finger muscles and muscles operating over the wrist and the elbow. Their primary influence on the grip force and the load force are indicated. During the preparatory actions prior to the impact the activity in all these muscles increased. This co-activation probably caused both an increased stiffness of the hand-arm 


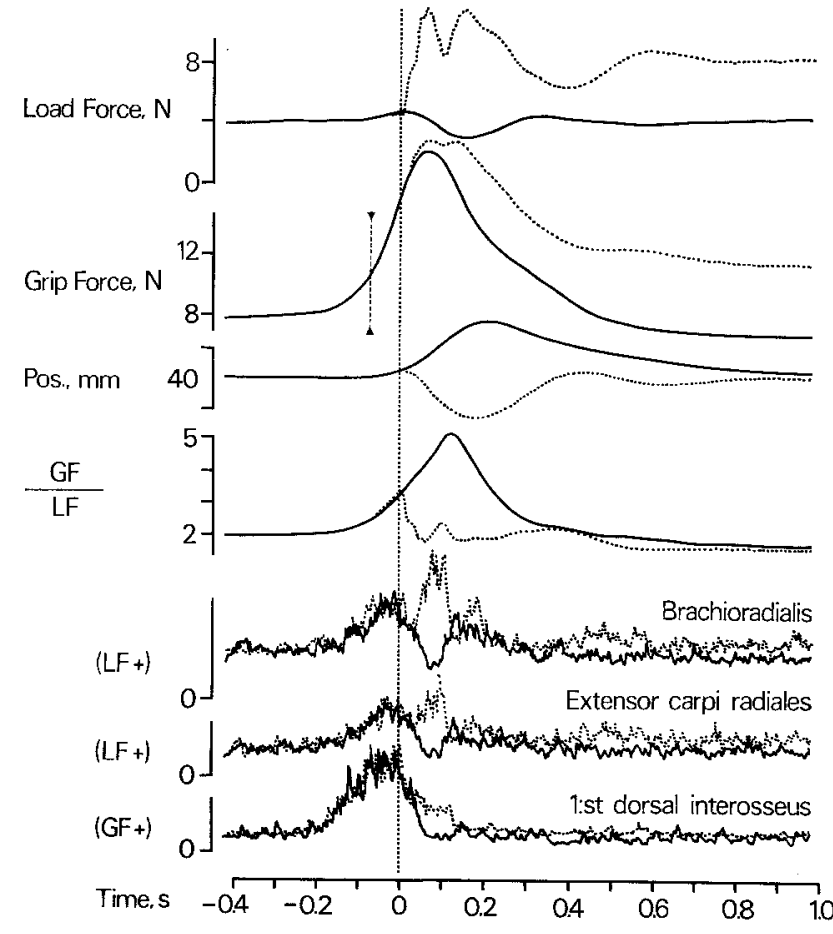

Fig. 4. Preparatory actions while the subject dropped the ball $(400 \mathrm{~g})$ studied in isolation by means of preventing the ball from reaching the target cup (grip apparatus $400 \mathrm{~g}$ ). Load force, grip force, vertical position, grip force/load force ratio (GF/LF) and r.m.s. processed e.m.g. signals from three hand/arm muscles as a function of time. The ball was prevented from hitting the target surface (-, averaged data from 24 trials) or the ball hit the target surface (. . . . . . averaged data from 56 trials) in the same series. Vertical dotted line indicates the moment the ball hits the target cup during the ordinary trials (time $=0$ ). Grip surface suede. Averaged data were synchronized in time at a preassigned grip force level $(10 \mathrm{~N})$ as indicated by the vertical dashed line with arrow-heads (there was no moment of collision available for synchronization). Single subject. For further explanation see Fig. 3 and text

system during the impact and the overt mechanical actions considered above. The fall in the muscle activity close to the impact indicates that the drive to these muscles was accurately timed to the mechanical events.

Following the impact the separate muscles all showed brief but clear excitatory activity peaks (peak-take-off points indicated by arrow-heads in Fig. 3). This increase in muscle activation was triggered by the impact as will be shown below. In the proximal arm muscles the latencies from the load force increase to the take-off points of the e.m.g. peaks were fairly short - 35-40 ms. The corresponding latencies for the distal hand muscles were considerably longer - 55-65 ms. These parallel increases in the activation of antagonists suggest that the triggered responses, like the preparatory responses, caused an increase in the stiffness of the arm/hand system. However, the triggered responses probably also contributed to the second, smaller, load force peak related to the repositioning of the grip apparatus in the air and the continuation of the grip force increase after the impact (see below). The magnitudes of these e.m.g. responses varied between individuals, and the size of the grip force increase after the impact varied accordingly. The latter response varied from ca. $5 \%$ to $65 \%$ of the size of the preparatory grip force increase defined as the difference in grip force at the load force peak and the static grip force one second before the impact.

Preparatory actions in isolation. The preparatory actions were studied in isolation during trials in which the ball, dropped by the sightless subject, was captured in the air by the experimenter before it hit the target. As illustrated in Fig. 4 the preparatory grip force increase and lifting movement (solid curves) were the same as in control trials in which the ball hit the grip apparatus (dotted curves). The differences appeared after the impact. Not surprisingly, there were no triggered e.m.g. peaks when the impact was prevented. Rather, in all eight muscles recorded from, there were dips in the electrical activity during the periods when these peaks would have appeared. Also note that the motor commands causing the preparatory elevation resulted in an excessive lifting movement if not moderated by the momentum of the ball.

The motor behavior during control trials with the subject's eyes closed and when there were no interferences by the experimenter was similar to that during trials with open eyes and no interference, indicating that visual input was not necessary for an appropriate performance. In addition, there were no obvious differences with and without visual input in trials in which the ball was prevented from hitting the target cup.

\section{Adjustments of the preparatory responses}

Assuming that the preparatory actions serve to prevent slips and large position deviations, these actions should match the size of the load force step, i.e. the impulse transferred to the hand/arm somehow should be taken into account during the programming of these actions. To test this idea, we changed the impulse between trials by pseudorandomly altering the weight of the ball, the weight of the grip apparatus or the length of the drop. Likewise, we also tested whether the frictional condition between the skin and the grip surface influenced the preparatory grip force increase. 

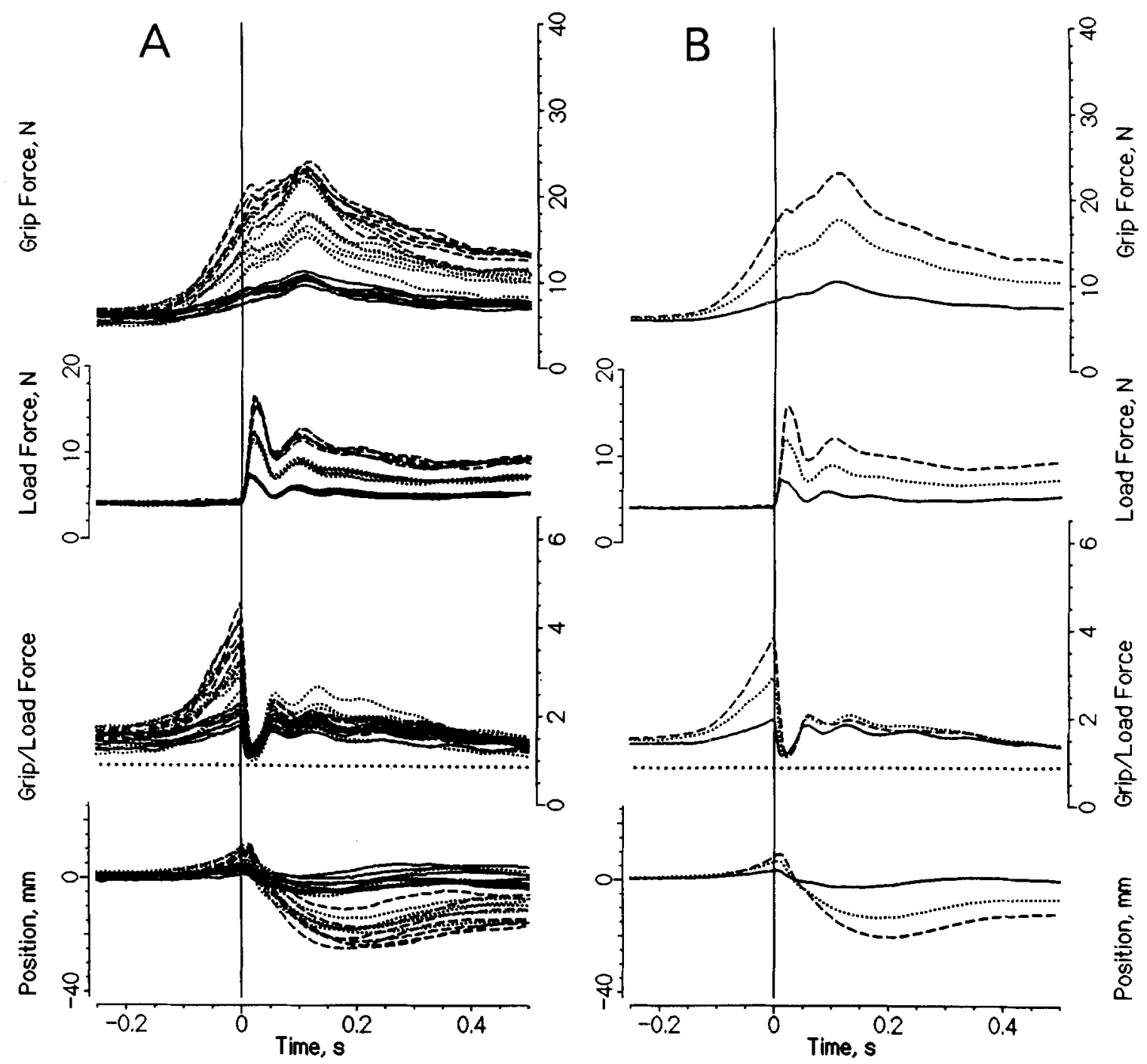

Fig. 5A, B. Influences of the weight of the ball on the preparatory actions while the subject dropped the ball. Grip force, load force, grip force/load force ratio and vertical position as a function of time. The weight of the ball was pseudorandomly varied between trials: $100 \mathrm{~g}$ $(-), 300 \mathrm{~g}(\ldots \ldots)$ and $500 \mathrm{~g} \mathrm{(-} \mathrm{.} \mathrm{-} \mathrm{-} \mathrm{)} \mathrm{balls.} \mathrm{The} \mathrm{weight} \mathrm{of} \mathrm{the} \mathrm{grip} \mathrm{apparatus}(400 \mathrm{~g})$ and the drop size $(\mathrm{ca} .4 \mathrm{~cm})$ were constant. A All 22 trials by a single subject superimposed. B Data averaged from the same 22 trials. Horizontal dotted lines indicate estimated slip ratio. Vertical lines indicate the moment the ball hits the target cup of the grip apparatus (time $=0$ ). Grip surface suede

Influence of the weight of the ball. As seen in Fig. 5, the heavier the ball the greater the rate of the preparatory grip force increase and the stronger the grip force at impact. In contrast, the duration of the grip force increase was approximately constant. This variation in the grip force level at the impact apparently matched the variations in the load force peaks caused by the differences in the dropped weights. The force ratio appeared to be a critically controlled parameter. It did not go below the slip ratio indicated by the horizontal dotted line (Fig. 5). Its minimum value at the load force peak was approximately the same for all three ball weights. It was concluded that the preparatory increase in the grip force was pur- posefully adjusted to the weight of the ball since an adequate safety margin was maintained to prevent slips during the critical period of the impact.

The preparatory lifting movement also varied with the ball weight in a manner similar to that of the grip force - again suggesting that the motor commands accounting for the grip force and for the lifting movement were coordinated. However, this adjustment did not fully compensate for the variation in the ball weight because the downward movement following the impact was larger for the heavier balls.

To account for the adaptation to the weight of the ball during the programming of the preparatory actions, information related to its weight must have 

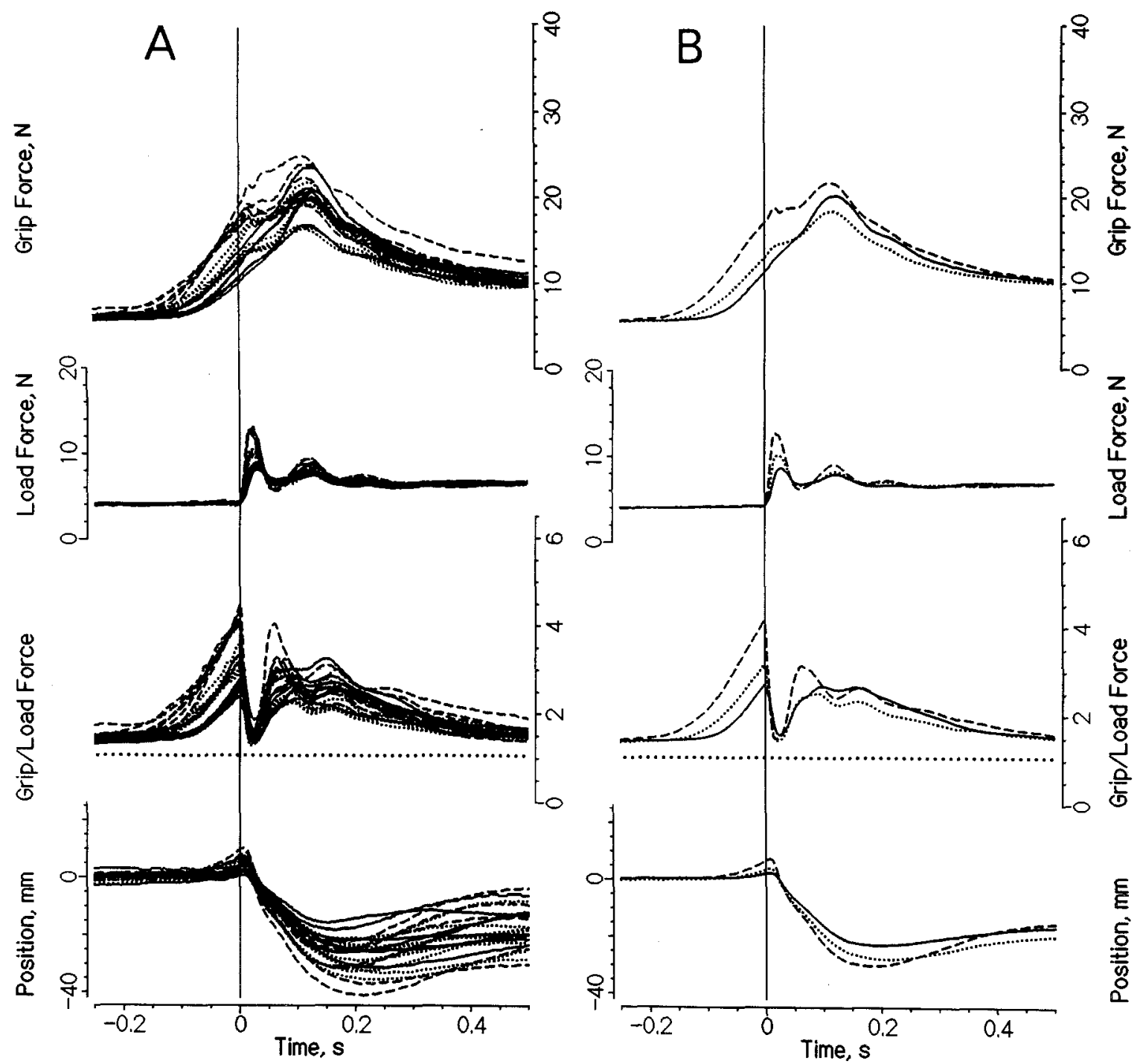

Fig. 6A, B. Influences of the size of the drop on the preparatory actions while the subject dropped the ball. The distance the ball fell was pseudorandomly varied between trials: $2 \mathrm{~cm}(-), 4 \mathrm{~cm} \mathrm{( \ldots ..)} \mathrm{and} 8 \mathrm{~cm} \mathrm{(-} \mathrm{.} \mathrm{-} \mathrm{-)} \mathrm{drop.} \mathrm{Weight} \mathrm{of} \mathrm{ball} \mathrm{(300} \mathrm{g)} \mathrm{and} \mathrm{weight} \mathrm{of} \mathrm{grip}$ apparatus $(400 \mathrm{~g}$ ) constant. A All 22 sample trials from a single subject superimposed. B Data averaged from the same 22 trials. Horizontal dotted lines indicate estimated slip ratio. Grip surface suede. For further details see legend to Fig. 5

entered and been utilized while the ball was handled with the contralateral hand; there were no obvious influences of the weight of the ball during the previous trial and no visual cues were available since the balls had the same visual appearance.

Influence of the length of the drop. The length of the drop was varied to change the velocity of the ball at the impact and thereby to cause variations in the load force peak. As shown in Fig. 6, these variations were adequately compensated for by alterations in the preparatory grip force response. Primarily the duration of the preparatory grip force, rather than the rate of the grip force change was increased: the higher the drop, the longer the period of grip force increase. The high precision in this adaptation is illustrated by curves representing the force ratio. Note the concurrence of a nearly identical minimum grip/load force ratio for all ball drop lengths. Again, the safety margin at the load force peak was adequately maintained. The influence on the preparatory elevation of the grip apparatus seemed to follow the same pattern as that on the grip force: the longer the ball-drop length, the longer the period of upward acceleration. Two of the subjects, however, preferred to use a different strategy. They achieved the same regulatory goal mainly by varying the rate of the grip force increase and the rate of the preparatory elevation. Regarding the sensory information utilized during the adaptation to the length of the drop, it 

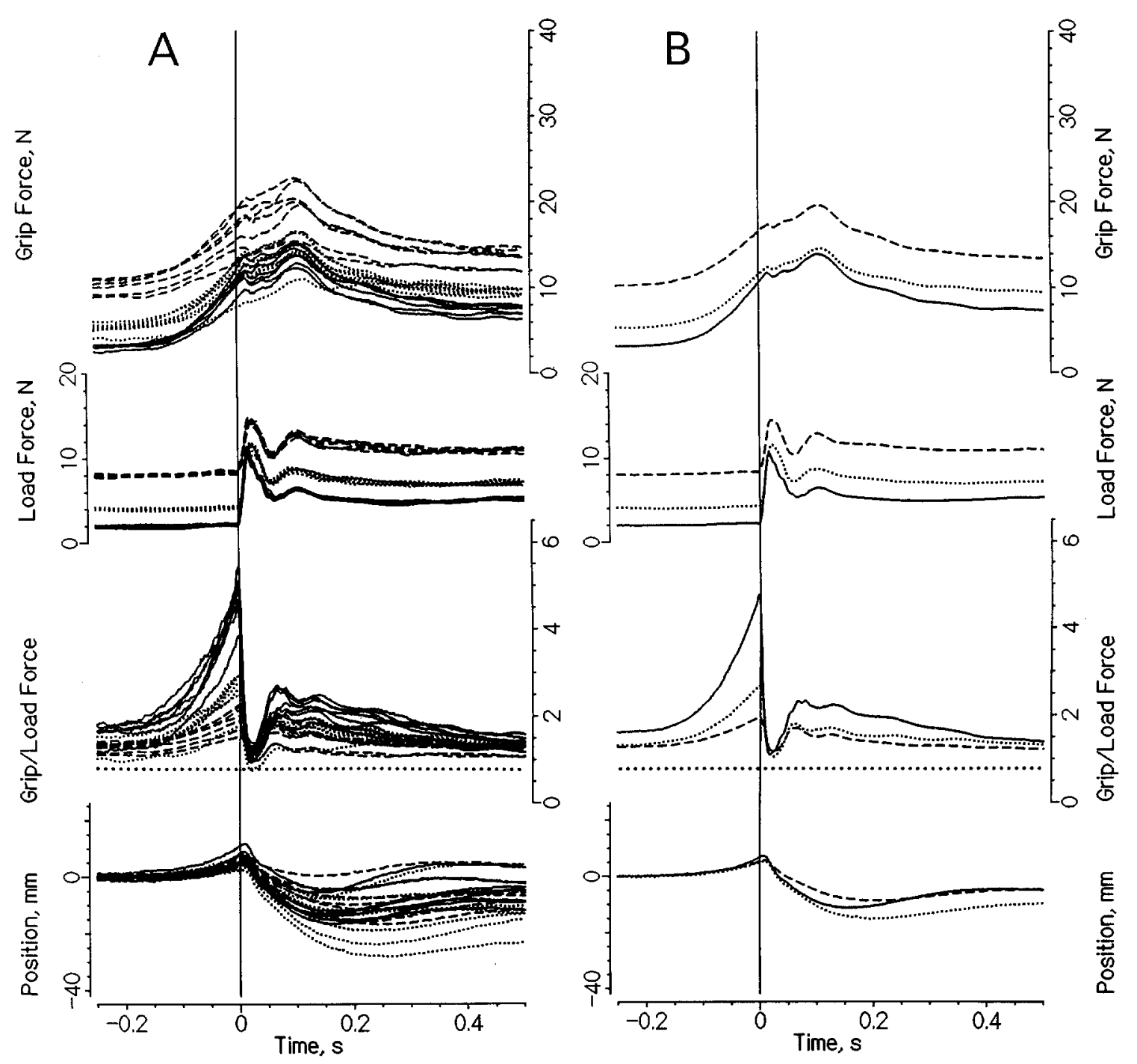

Fig. 7A, B. Influences of the weight of the grip apparatus on the preparatory actions while the subject dropped the ball. The weight of the test object was pseudorandomly varied between trials: $200 \mathrm{~g}(-), 400 \mathrm{~g}(\ldots \ldots)$ and $800 \mathrm{~g}(-\ldots$. . - grip apparatus. Weight of ball $(300 \mathrm{~g})$ and size of drop (ca. $4 \mathrm{~cm})$ constant. A All 22 sample trials from a single subject superimposed. B Data averaged from the same 22 trials. Horizontal dotted lines indicate estimated slip ratio. Grip surface suede. For further details see legend to Fig. 5

seems reasonable to assume that visual signals might have played a role. However, in experiments with blindfolded subjects who had practiced the task in advance with vision, it was found that they adjusted their preparatory responses to the size of the drop in the blind condition.

Influences of the weight of the grip apparatus. The impulse transferred through the grip apparatus to the subject will be influenced by the weight of the grip apparatus: the heavier the weight, the smaller the impulse, and the smaller the load force peak. In a separate series of trials, the weight of the grip apparatus was changed pseudorandomly. As illustrated in Fig. 7, the resulting variation in the load force peak was adequately taken into account by adjustments in the grip force rate in a manner similar to that during changes in the mass of the ball. Again, the minimum force grip/load force ratio at the impact provided an adequate safety margin to prevent slips.

The most obvious factors determining the magnitude of the load force change at the impact are those considered above. Other factors related to the momentum transferred to the subject's arm include the elastic properties of the grip apparatus, the mass and visco-elastic properties of the hand/arm system, and the rebound coefficient of the ball and its target surface. When the dampening material reducing the rebound was removed, the load force peak became much sharper and higher. During this condition the minimum force ratio was kept approximately constant but was often lower than the slip ratio for a very short period of time (sharp negative peak). This, however, did not induce slips. 

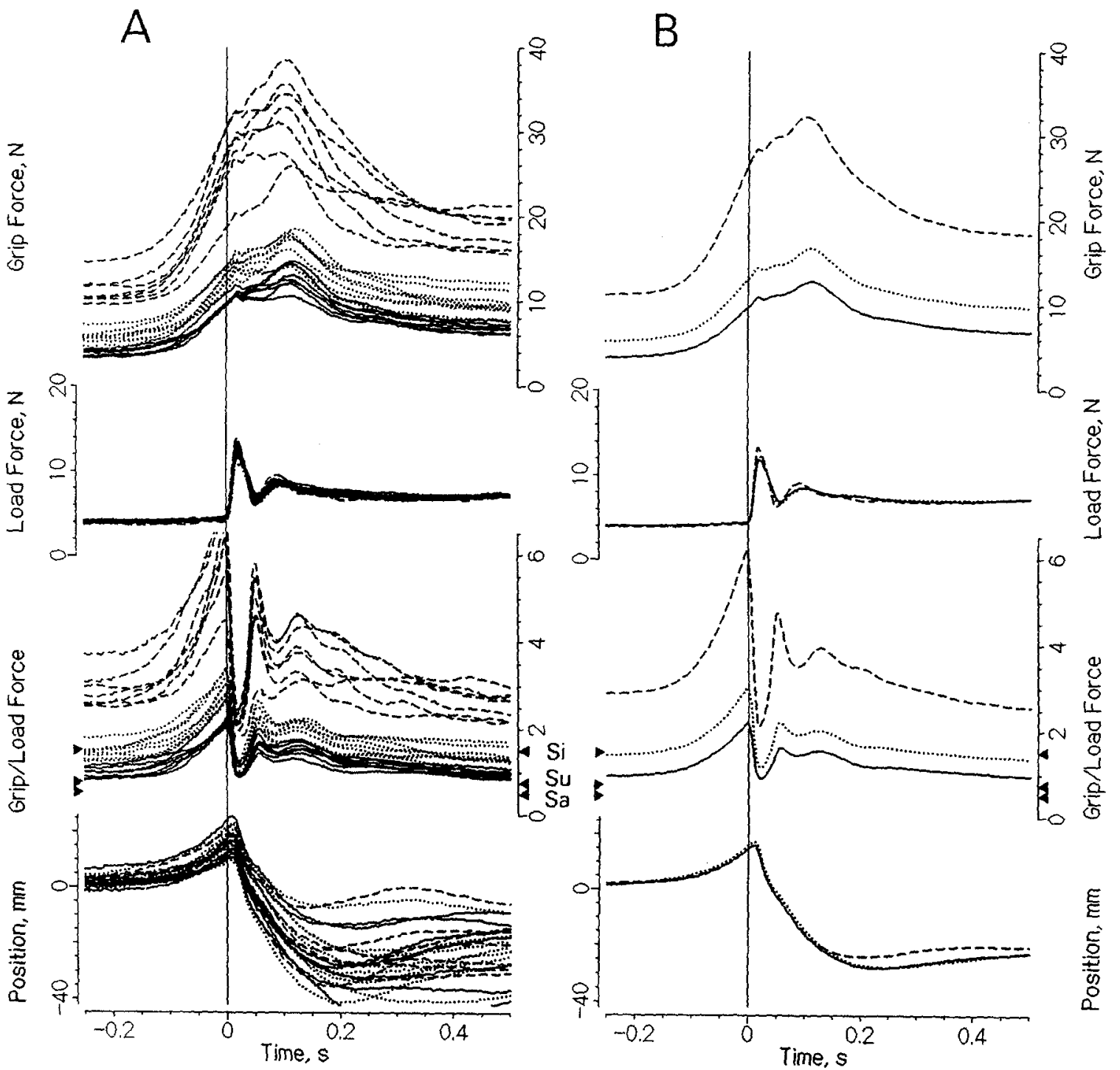

Fig. 8A, B. Influences of the friction between the grip surface and the skin on the preparatory actions while the subject dropped the ball. The grip surface structure was pseudorandomly varied between trials: sandpaper $(-$, least slippery surface material), suede (. . . . .) and silk (..... , most slippery surface material). Weight of ball $(300 \mathrm{~g})$, weight of grip apparatus $(400 \mathrm{~g})$ and drop distance (ca. $4 \mathrm{~cm})$ constant. A All 22 sample trials from a single subject superimposed. B Data averaged from the same 22 trials. Arrowheads indicate mean slip ratios for the three different pairs of grip surfaces. For further details see legend to Fig. 5

Influence of the friction between the skin and the grip surface. In agreement with previous findings, the frictional variation between the skin and the grip surface influenced the ratio between the grip and load forces throughout the trials; the more slippery the material, the higher the ratio (Johansson and Westling 1984b). As illustrated in Fig. 8, not only the static grip forces but also the size of the preparatory grip force increase was greater when the grip surface was more slippery, i.e. the preparatory ratio increase was approximately proportional to the level of the static ratios before the preparatory actions (weight of ball and grip apparatus constant). By the frictional influences on the grip force rates, the magnitude of the preparatory grip increase was adequately adapted to the frictional condition: the negative peaks of the force ratio curves referring to the different frictional conditions were scaled to the corresponding slip ratios (indicated by arrows-heads in Fig. 8) providing appropriate safety margin. Again, the minimum ratio at the impact did not pass the critical slip ratio. There were no obvious influences of the grip surface on the load force and position signals.

\section{Experimenter drops the ball}

Not surprisingly, if the experimenter dropped the ball unexpectedly into the "cup" of the grip 


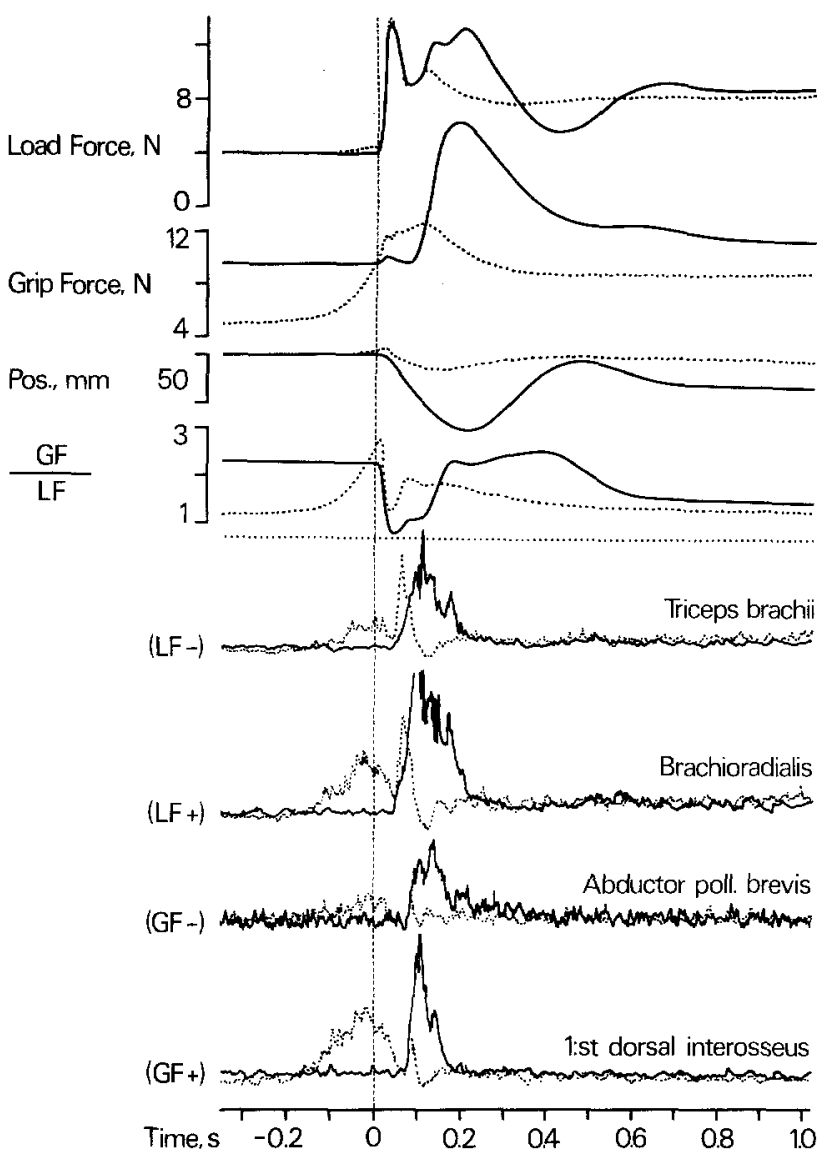

Fig. 9. Mechanical actions and e.m.g. activity associated with the rapid load force increase caused by the experimenter dropping the ball. Load force, grip force, vertical position, grip force/load force ratio and r.m.s. processed e.m.g. signals from 4 different hand/arm muscles as a function of time. The ball was dropped by the experimenter ( - , averaged data from 24 trials) or the subject dropped the ball using the contralateral hand $(. . .$, . averaged data from 24 trials, see Fig. 3). Vertical dashed line indicates the moment the ball $(400 \mathrm{~g})$ hits the grip apparatus $(400 \mathrm{~g})$. Data averaging synchronized in time at this moment. Single subject. Grip surface suede. Note that preparatory responses are present only if the subject drops the ball

apparatus held by a blindfolded subject, the object was accidentally dropped except if the ball was quite light (generally $<200 \mathrm{~g}$ with a $400 \mathrm{~g}$ grip apparatus). Hence, in the absence of preparatory grip actions, the force ratio fell below the slip ratio. With a $100 \mathrm{~g}$ ball, which usually did not cause overall slips, a pronounced grip force increase appeared $70-80 \mathrm{~ms}$ after the impact. After reaching its peak ca. $0.1 \mathrm{~s}$ later, the grip force decayed to a new static value which was adapted to the new higher weight of the grip apparatus. The grip force peak was strong. It was in the same order of magnitude as the peak of the preparatory grip force response when the subject let a $400 \mathrm{~g}$ ball fall.

However, with repetitive trials with a heavier ball, the problem with the accidental slips was overcome by voluntarily increasing the grip force and thereby the force ratio - during subsequent trials until successful. This new force ratio was attained early during the lifting of the grip apparatus and approximately the same force ratio was employed in the subsequent trials in a seemingly automatic fashion. Successful trials with a $400 \mathrm{~g}$ ball are illustrated by the solid curves in Fig. 9. (For comparison, the dashed curves represent corresponding trials in which the subject controlled the release of the ball.) In spite of the high force ratio there was a strong grip force response starting 70-80 ms after the onset of the impact. The magnitude of the grip force increase was often more than twice the total grip force increase when the subject dropped the same ball. Although, the triggered response appeared too late to be useful to prevent slips (i.e. the force ratio had its minimum prior to the appearance of the grip force response), it accounted for a quick restoration of the force ratio to a value similar to that used prior to the impact. Accordingly, as for the preparatory grip responses, the intensities of the triggered responses were stronger the heavier the ball. Interestingly, ca. $0.5 \mathrm{~s}$ after the impact of the individual trials the subjects often preferred to loosen the grip and decrease the ratio of values normally used (Fig. 9).

In parallel with the triggered grip force responses, there was also a pronounced load force increase (Fig. 9) - again supporting the notion of a coordinated force output. Regarding the position signal, the initial deviation was much larger than that observed when the subject dropped the ball. This probably occurred because of the absence of the preparatory upward movement of the arm and the absence of an adequate preparatory stiffening of the hand/arm system. The strong response observed in the load force was also reflected in the position signal, i.e. after the initial downward movement the quick repositioning movement was often characterized by a pronounced overshoot.

The e.m.g. records revealed that contractions were triggered in all eight muscles measured although only four are illustrated (Fig. 9). Thus, it seems as if the motor commands triggered by the impact caused a general increase in the stiffness of the $\mathrm{arm} / \mathrm{hand}$ system in addition to the overt mechanical responses. The latencies between the impact and the appearance of these e.m.g. responses were approximately the same as with the triggered responses observed when the subject dropped the ball (Fig. 9). Hence, similar neural pathways might have been engaged. However, as might be predicted from the mechanical data, the e.m.g. responses were much stronger in all muscles recorded from when the ball was dropped by the experimenter. This was true also 
if the initial load peaks were of the same size during the two conditions (Fig. 9). A stronger e.m.g. responses when the ball was dropped unexpectedly also is in agreement with the findings represented in Fig. 4, indicating that the motor commands executing the preparatory actions caused a decreased excitation of the motoneurones specifically during the period at which the triggered responses normally appeared. Since this was the case also with muscles influencing the grip force, the modulation in responsiveness could not be explained on the basis on autogenic reflex mechanisms (i.e. "loading" and "unloading" responses). Neither could the stronger responses be explained by an increased excitability in motoneuron pools related to the higher grip forces maintained prior to the impact. If the subject was asked to intentionally grip even firmer (e.g. double the grip force) the triggered responses remained approximately the same. Despite the fact that these responses during the "passive" condition showed higher amplitudes and were more extended in time, the rise time of the responses observed in the arm muscles often was slower (Fig. 9). Interestingly, this tendency was less marked if the subject was allowed to look at the grip apparatus/ball. Likewise, for some subjects, the latency of the triggered responses was increased by ca. $5 \mathrm{~ms}$ during the blindfolded condition as compared with the sighted condition (Ikuta K, Forssberg H., Johansson R.S., Westling G., manuscript in preparation).

\section{Discussion}

During elementary lifting tasks using the precision grip, the motor commands appear to be generated primarily on the basis of an internal representation of certain physical properties of the lifted object acquired in previous lifts, i.e. its frictional properties and weight. During erroneous programming, somatosensory signals may cause compensatory actions and update various parameters of the internal model (Johansson and Westling 1984b, 1987, 1988). The present study indicates that similar principles also may apply during further manipulative actions superimposed on the basic grip.

\section{Preparatory actions}

The nature of the preparatory actions observed prior to the rapid load increase caused by the subject dropping the ball into the target cup clearly indicates anticipatory parameter setting of motor programs, i.e. relevant motor-program parameters were adjusted prior to the execution of the preparatory actions. These actions apparently served to prevent slips and large position deviations. Consequently, they were influenced by various factors related to the momentum of the dropped weight and the momentum transferred through the grip apparatus. Hence, the control processes would possess knowledge about the dynamics of the interactions between the lifted object and the dropped weight. Another important factor was the coefficient of friction between the skin and grip apparatus. Owing to all these influences an appropriate safety margin was maintained during the crucial period at the impact. It appears as if the minimum grip force/load force ratio at the impact actually was a critical control point.

To account for the adjustment of the preparatory responses to the weight of the ball, information related to its mass must have been obtained during the handling of the ball with the contralateral hand since the subject could not visually discriminate the balls. Similarly, the adjustment of the preparatory responses to the mass of the grip apparatus must have been based on information obtained when the grip apparatus was lifted (see Johansson and Westling 1988). This kind of information might have been derived from peripherally-arising somatosensory input and/or from internal signals generated in conjunction with the commands for muscular contractions (e.g. McCloskey 1974; McCloskey et al. 1983).

The adaptation of the preparatory responses to alterations in the distance the ball fell by the force of gravity was principally done by adjusting the duration of the preparatory grip force increase and the duration of the simultaneously occurring elevation of the grip apparatus. This strategy contrasts with that used to compensate for variations in the weight of the ball and the weight of the grip apparatus, i.e. by adapting the rate (and not the duration) of the preparatory actions. The prolongation of the preparatory responses with increasing length of the drop may have been, at least partly, caused "passively" by the lengthening in the time of the drop. (A fall of $2 \mathrm{~cm}, 4 \mathrm{~cm}$ and $8 \mathrm{~cm}$ theoretically takes $63 \mathrm{~ms}, 89 \mathrm{~ms}$, and $126 \mathrm{~ms}$, respectively; air resistance not taken into account). However, additional mechanisms might have been involved since two of the subjects preferred to use a different strategy. Hence, at present we cannot rule out that proprioceptive or re-afferent signals related to the distance between the hands were utilized during the adaptation of the preparatory responses. Likewise, if available, visual cues might play a role. In any case, some kind of internal representation of the spatial aspects of the grip apparatus and the ball must have been utilized together with knowledge of the kinetics of a freely falling mass. 
As to the friction between the grip surface and the skin, the present findings are consistent with the idea that friction via a sensorimotor memory sets the ratio between the rate of change of the grip and load forces by modifying mainly the grip force rate (Johansson and Westling 1984b). Thus, the variations in friction did not influence the preparatory elevation of the grip apparatus but only altered the grip force rate.

The high precision in the timing of the preparatory grip force adjustments, reflected as nearly constant minimum force ratios at the impact, indicates that the moment of impact was anticipated accurately. Hence, the muscle commands accounting for the preparatory actions and those accouting for the release of the ball by the contralateral hand were coordinated precisely in time. The release of the ball (ca. $90 \mathrm{~ms}$ prior to the impact at a $4 \mathrm{~cm}$ drop) could not have provided a trigger for the onset of the preparatory actions of the target hand since these were approximately halfway completed at this moment (they were initiated ca. $150 \mathrm{~ms}$ prior to the impact at a $4 \mathrm{~cm}$ drop). Thus, the moment the ball was released was somehow controlled in relation to the course of the preparatory actions of the contralateral hand. Preliminary findings indicate that cutaneous input providing information related to the frictional condition between the fingers and the ball may be required for this control (unpublished data, R.S. Johansson and G. Westling).

During the preparatory actions there was an increased activity in all hand and arm muscles from which recordings were made. Since a co-contraction of antagonistic pairs of muscles implies an increased joint stiffness (e.g. Humphrey and Reed 1983) this finding suggests that the whole arm/hand system was stiffened prior to the impact. That the position deviation was small in the trials in which the subject dropped the ball as compared with trials in which the same ball was dropped unexpectedly by the experimenter also support the concept of an increased stiffness in the prepared state.

Responses triggered by the impact. Following the impact, triggered responses were observed in the grip and load forces. These responses were more pronounced when the impact appeared unexpectedly than when the subject him/herself caused a similar load change. In the unexpected case, if an overall slip did not occur, the triggered actions seemed to be functional in that they contributed to quickly restoring the vertical position of the object (lifting response), and the force ratio (grip force response), and thereby the safety margin. In the prepared case, the need for these responses was less due to his/her preparatory actions. Indeed, the motor programs controlling the preparatory actions also appeared to strongly depress the size of the triggered responses. This depression was also reflected in a short-term reduction in the motoneuronal excitability occurring specifically during the period of the triggered e.m.g. peaks. This change in responsiveness may be comparable to variations in triggered compensatory responses observed during a variety of movements in man and animals (Frossberg et al. 1975; Forssberg et al. 1977; Dufresne et al. 1978; Day et al. 1983; Gracco and Abbs 1985). The change in responsiveness also resembles the reciprocal interactions between automatic "long-latency" reflex events and later "voluntary" phases of correction described for thumb movements (Rothwell et al. 1982).

Triggered responses were observed in all antagonist pairs of arm and hand muscles and all the recordings showed qualitatively the same e.m.g. pattern. Hence, as with the preparatory actions, the triggered responses would have accounted for a general increase in the stiffness of the hand/arm system in parallel to the observed force responses. This pattern of muscular activation contradicts the widely accepted reflex model implying that only the muscle being stretched is excited and the activity in the antagonist is depressed, i.e. Sherrington's original concept of reciprocal innervation as a general reflex model for voluntary movements (Sherrington 1906). The nonautogenic nature of the triggered responses was further emphasized by the triggered increase in the grip force (see also Johansson and Westling 1988).

The response latencies were similar to those of various "long-latency" stretch reflexes (or "M2" responses) in hand and arm muscles (Hammond 1956; Marsden et al. 1976; Lee and Tatton 1975), which commonly are considered to be supraspinally mediated (Phillips and Porter 1977; Desmedt 1978; Marsden et al. 1983; Lee et al. 1983; however cf. Darton et al. 1985). The study of these reflexes has been limited almost exclusively to actions around a single joint. The function of the observed autogenic muscle responses has remained an engima, but a number of hypotheses have been proposed (see Lee et al. 1983; Marsden et al. 1983). However, there are recent studies on more complex (and more natural) automatic compensatory actions to external disturbances requiring coordinated control among multiple hand/arm muscles and joints (Traub et al. 1980; Marsden et al. 1981; Cordo and Nashner 1982; Cole et al. 1984; Lacquaniti and Soechting 1984; Cole and Abbs 1987; Johansson and Westling 1988). In these investigations, the muscle response latencies are generally in the same order of magnitude as the "long-latency" stretch reflexes. These studies also 
have emphasized that the response characteristics heavily depend upon the goal, the context of the specific movement, and the characteristics of the external disturbances, i.e. features often ascribed to "long latency" stretch reflexes observed with single joint movements. Moreover, as in the present task, these more complex compensations are manifest the first time a subject experiences a perturbation. From this background it seems plausible that "longlatency" reactions in general represent the expression of the release of prestructured sets of motor commands (cf. Crago et al. 1976), and that the autogenic response components merely represent particular ingredients of these commands. Hence, in experiments restricted to single joint actions, the autogenic responses would dominate the picture. Comparable sensorimotor actions involving autogenic and nonautogenic components have been demonstrated also with other systems: during rapid postural adjustments in stance (Nashner et al. 1979; Nashner and Cordo 1981), eye-head movements (Bizzi et al. 1971; Morasso et al. 1973), and speech movements (Gracco and Abbs 1985).

Along those lines, the function of the neural mechanisms accounting for the "long-latency" responses in the hand/arm system would be to organize task-dependent muscle synergies constituting various automatic components of voluntary movements. Such task-related synergies would represent a high level of adaptability based on integration among multimodal sensory information and previous experiences. Perhaps the functional dominance of the most likely supraspinally mediated "longlatency" responses over short-latency spinal responses in the hand muscles reflects the demanding need of the motor control apparatus to fulfill this assignment. In accordance with this view, in the less flexible lower extremities compensatory motor responses elicited by perturbations appear, to a much higher degree, to be initiated by spinal mechanisms.

With the intrinsic hand muscles the response latencies were about the same as with the automatic grip force responses to slips while holding objects (Johansson and Westling 1987). Likewise, one purpose of the grip force responses triggered by the impact seemed to be to increase the grip force to obtain an appropriate safety margin. However, in contrast to the slip responses, the grip force responses triggered by the impact only compensated for the new higher load force and did not cause a maintained change in the ratio between the grip force and the load force. Medical Research Council (project 3548), Gunvor and Josef Aners
Stiftelse, and the University of Umeå. The technical assistance of Mr. A. Bäckström, Mr. L. Bäckström, and Mr. J. Ringquist is gratefully acknowledged. The informed consent of all subjects was obtained according to the declaration of Helsinki.

\section{References}

Belen'kii VY, Gurfinkel VS, Pal'tsev YI (1967) Elements of control of voluntary movements. Biofizika (Moskva) 12: $135-141$

Bizzi E, Kalil R, Tagliasco V (1971) Eye-head coordination in monkeys: evidence for centrally patterned organization. Science 173: 452-454

Cole KJ, Abbs JH (1987) Kinematic and electromyographic responses to perturbation of a rapid grasp. J Neurophysiol 57 (in press)

Cole KJ, Gracco VL, Abbs JH (1984) Autogenic and nonautogenic sensorimotor actions in the control of multiarticulate hand movements. Exp Brain Res 56: 582-585

Cordo PJ, Nashner LM (1982) Properties of postural adjustments associated with rapid arm movements. J Neurophysiol 47: 287-302

Crago PE, Houk JC, Hasan Z (1976) Regulatory actions of human stretch reflex. J Neurophysiol 39: 925-935

Darton K, Lippold OCJ, Shahani M, Shahani U (1985) Longlatency spinal reflexes in humans. J Neurophysiol 53: 1604-1618

Day BL, Rothwell JC, Marsden CD (1983) Interaction between the long-latency stretch reflex and voluntary electromyographic activity prior to a rapid voluntary motor reaction. Brain Res 270: 55-62

Desmedt JE (ed) (1978) Cerebral motor control in man: long loop mechanisms, Vol 4. Karger, Basel

Dietz V, Noth J, Schmidtbleicher D (1981) Interaction between preactivity and stretch reflex in human triceps brachii during landing from forward falls. J Physiol (Lond) 311: 113-125

Dufresne JR, Gurfinkel VS, Soechting JF, Terzuolo CA (1978) Response to transient disturbances during intentional forearm flexion in man. Brain Res 150: 103-115

Forssberg H, Grillner S, Rossignol S (1975) Phasic dependent reflex reversal during walking in chronic spinal cats. Brain Res 85: 103-107

Forssberg H, Grillner S, Rossignol S (1977) Phasic gain control of reflexes from the dorsum of the paw during locomotion. Brain Res 132: 121-139

Gracco VL, Abbs JH (1985) Dynamic control of the perioral system during speech: kinematic analysis of autogenic and nonautogenic sensorimotor processes. J Neurophysiol 54: 418-432

Hammond PH (1956) The influences of prior instructions to the subject on an apparently involuntary neuro-muscular response. J Physiol (Lond) 132: 17P-18P

Hugon M, Massion J, Wiesendanger M (1982) Anticipatory postural changes induced by active unloading and comparison with passive unloading in man. Pflügers Arch 393: 292-296

Humphrey DR, Reed DJ (1983) Separate cortical system for control of joint movement and joint stiffness: reciprocal activation and coactivation of antagonist muscles. In: Desmedt JE (ed) Motor control mechanisms in health and disease. Raven Press, New York, pp 347-372

Johansson RS, Westling G (1984a) Influences of cutaneous sensory input on the motor coordination during precision manipulation. In: von Euler C, Franzen $O$, Lindblom U, Ottoson D (eds) Somatosensory mechanisms. Macmillan Press, London, pp 249-260 
Johansson RS, Westling G (1984b) Roles of glabrous skin receptors and sensorimotor memory in automatic control of precision grip when lifting rougher or more slippery objects. Exp Brain Res 56: 550-564

Johansson RS, Westling G (1987) Signals in tactile afferents from the fingers eliciting adaptive motor responses during precision grip. Exp Brain Res 66: 141-154

Johansson RS, Westling G (1988) Coordinated isometric muscle commands adequately and erroneously programmed for the weight during lifting tasks with precision grip. Exp Brain Res 71: $59-71$

Lacquaniti F, Soechting JF (1984) Behavior of the stretch reflex in a multi-jointed limb. Brain Res 311: 161-166

Lee RG, Murphy JT, Tatton WG (1983) Long-latency myotatic reflexes in man: mechanisms, functional significance, and changes in patients with Parkinson's disease or hemiplegia. In: Desmedt JE (ed) Motor control mechanisms in health and disease. Raven Press, New York, pp 489-508

Lee RG, Tatton WG (1975) Motor responses to sudden limb displacements in primates with specific CNS disorders and in human patients with motor system disorders. Can J Neurol Sci 2: $285-293$

Marsden CD, Merton PA, Morton HB (1981) Human postural responses. Brain 104: 513-534

Marsden CD, Merton PA, Morton HB (1976) Servo action in the human thumb. J Physiol (Lond) 257: 1-44

Marsden CD, Rothwell JC, Day BL (1983) Long-latency automatic responses to muscle stretch in man: origin and function. In: Desmedt JE (ed) Motor control mechanisms in health and disease. Raven Press, New York, pp 509-539

McCloskey DI (1974) Muscular and cutaneous mechanisms in the estimation of the weights of grasped objects. Neuropsychologia $12: 513-520$
McCloskey DI, Gandevia S, Potter ED, Colebatch SG (1983) Muscle sense and effort: motor commands and judgments about muscular contractions. In: Desmedt JE (ed) Motor control mechanisms in health and disease. Raven Press, New York, pp 151-168

Melvill-Jones G, Watt DGD (1971) Observations on the control of stepping and hopping movements in man. J Physiol (Lond) 219: 709-727

Morasso P, Bizzi E, Dichgans J (1973) Adjustments of saccade characteristics during head movements. Exp Brain Res 16: 492-500

Nashner LM, Cordo PJ (1981) Relation of automatic and postural responses and reaction-time voluntary movements of human leg muscles. Exp Brain Res 43: 395-405

Nashner LM, Woollacott M, Tuma G (1979) Organization of rapid responses to postural and locomotor-like perturbation of standing man. Exp Brain Res 36: 463-476

Phillips CG, Porter R (1977) Corticospinal neurones. Academic Press, London

Rothwell JC, Traub MM, Marsden CD (1982) Automatic and "voluntary" responses compensating for disturbances of human thumb movements. Brain Res 248: 33-41

Sherrington CS (1906) The integrative action of the nervous system, 2nd edn. Yale Univ Press, New Haven, CT

Traub JC, Rothwell JC, Marsden CD (1980) A grab reflex in the human hand. Brain 103: 869-884

Westling G, Johansson RS (1984) Factors influencing the force control during precision grip. Exp Brain Res 53: 277-284

Westling G, Johansson RS (1987) Responses in glabrous skin mechanoreceptors during precision grip in humans. Exp Brain Res 66: $128-140$

Received June 2, 1987 / Accepted December 11, 1987 